\title{
PENERAPAN ALGORITMA BINARY SEARCH DALAM PENCARIAN DATA POTENSI INVESTASI DI KABUPATEN SELUMA DENGAN SMARTPHONE
}

\author{
${ }^{1}$ Onsardi, ${ }^{2}$ Muntahanah, ${ }^{3}$ Rozali Toyib \\ 1,2,3 Universitas Muhammadiyah Bengkulu, Indonesia \\ I'onsardi@umb.ac.id ; ${ }^{2} m u n t a n a h a h @ u m b . a c . i d,{ }^{3}$ rozalitoyib@umb.ac.id
}

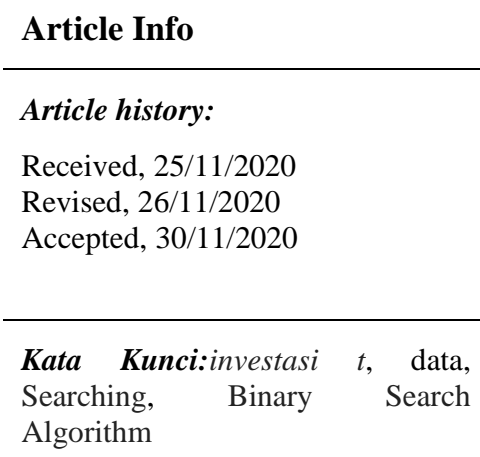

\begin{abstract}
ABSTRAK
Permasalahan dalam pengembangan potensi investasi di Kabupaten Seluma belum adanya akses data yang tersedia di Kabupaten Seluma yang berbentuk digital, yang adanya hanya berupa buku data potensi yang aksesnya terbatas dan tidak bisa secara global untuk itu dibutuhkan digitalisasi data dan sebuah aplikasi yang memudahkan orang atau badan melihat data potensi yang ada sehingga investor tertarik menanamkan modalnya. Aplikasi ini dilengkapi dengan pencarian untuk memudahkan pengguna mencari data yang dibutuhkan yaitu dengan menggunakan Algoritma Pencarian Binary Search yang mempunyai keunggalan dalam langkah-langkah pencariannya lebih mudah dan tidak memakan waktu. Berdasarkan hasil pengujian disimpulkan : potensi terbesar kabupaten Seluma adalah dari sektor pertanian, perikanan/peternakan kemudian pertambangan dan wisata, dalam penerpannya Algoritma Binary Search lebih efisien dan cepat dalam pencarian data yang dibutuhkan karena datanya sudah diurutkan dari awal dan kelemahannya adalah pencarian ini tidak dapat berfungsi maksimal jika datanya dari awal tidak diurutkan terlebih dahulu
\end{abstract}

\section{ABSTRACT}

Keywords: investment, data, search, binary Search algorithm

\begin{abstract}
The problem in developing investment potential in Seluma Regency is that there is no data access available in Seluma Regency which is in digital form, which only exists in the form of a potential data book with limited access and cannot globally for that, data digitization is needed and an application that makes it easy for people or bodies to see existing potential data so that investors are interested in investing. This application is equipped with a search to make it easier for users to find the required data, namely by using the Binary Search Search Algorithm which is unique in that the search steps are easier and do not take time. Based on the test results it is concluded: the greatest potential of Seluma district is from the agriculture, fishery / livestock sector then mining and tourism, in its application the Binary Search Algorithm is more efficient and fast in finding the required data because the data has been sorted from the start and the weakness is that this search cannot function maximum if the data is not sorted first.
\end{abstract}

This is an open access article under the CC BY-SAlicense.

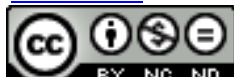

\section{Penulis Korespondensi}

Muntahanah

Teknik Informatika, Universitas Muhammadiyah Bengkulu

muntanahah@umb.ac.id

\section{PENDAHULUAN}

Kabupaten Seluma merupakan kabupaten pemekaran dari Kabupaten Bengkulu Selatan dengan luas wilayah wilayah laut seluas $\pm 1.728,02 \mathrm{~km}^{2}$ sehingga total keseluruhan luas Kabupaten Seluma adalah 4.128,46 km² yang terletak di Provinsi Bengkulu berdasarkan Undang-undang Pemekaran Wilayah No 3 Tahun 2003 dengan total luas $\pm 2.400,44 K M^{2}$, dalam pengembangan sesuai dengan aspirasi dan rencana pengembangan wilayah diman kabupaten seluma telah memekarkan kecamatan induk dari 15 kecamatan menjadi 14 kecamatan dimana setiap wilayah mempunyai 
potensi unggulan yang berbedah-bedah yang menarik investor untuk menanamkan modalnya seperti pertambangan batu bara, tambak udang, kebun sawit, hasil kerajinan berupa tenun tradisional dan objek-objek wisata yang menarik yang belum tereksplor secara luas. Potensi yang begitu besar dari kabupaten ini belum terkelola dengan baik dan masih minimnya informasi tidak memberi manfaat bagi penambahan pendapatan daerah ini, ini menjadi persoalan dari tahun ke tahunnya walaupun banyak usaha telah dilakukan untuk memperkenalkan potensi yang ada agar bisa dilirik investor dari luar. Pemerintah telah berusaha mengumpulkan data potensi tersebut dan mengemasnya dalam bentuk buku daerah, tetapi belum ada tindak lanjut yang kongkrit untuk pengembangan lebih lagi dari data tersebut dalam bentuk yang lebih maju sesuai dengan tuntutan era digital.

Digitalisasi sudah menjadi keharusan di era sekarang karena menjadi permasalahan dalam pengembangan potensi investasi yang ada karena dengan cara lama informasi yang disampaikan masih sangat terbatas sekali untuk itu dibutuhkan sebuah aplikasi yang bisa mengakomodir datadata itu dan aplikasi ini bisa di instal di smartphone yang memungkin semua orang bisa mengakses dan bisa menjangkau kalangan yang lebih luas dibandingkan dengan cara yang biasa, di mana investor dari luar bisa mengakses melalui browser menggunakan Komputer ataupu smarphone. Aplikasi ini dilengkapi dengan pencarian yang menerapkan Algoritma Binary Search dalam pencarian data potensi investasi.

Teknologi smartphone telah menciptakan perubahan besar di dalam dunia telekomunikasi karena sudah menjadi gaya hidup dan kebutuhan sehari-hari disamping sebagai alat komunikasi yang peredarannya sangat luas hamper menjangkau setiap kalangan masyarakat, dapt diperoleh dengan mudah dan murah[1].

Investasi merupakan komitmen antara perorangan atau perusahaan bias berupa tanah, emas mesin atau bangunan maupun aset finansial berupa deposite, saham atau obligasi dengan tujuan mempeoleh keuntungan baik karena harga saham atau sejumlah dividen di masa yang akan datang dalam jangka waktu tertentu, Investasi akan memunculkan proses produksi atau output yang dihasilkan yang merupakan faktor yang mempengaruhi perkembangan ekonomi dan kesempatan kerja yang lebih luas di suatu daerah[2][3].

Proses pencarian data yang disimpan di dalam penyimpanan data digunakan suatu algoritma pencarian yang lebih luasi dikenal dalam bahas inggrisnya yaitu search proses untuk memudahkan mencari data yang dibutuhkan, Algoritma Binary Search dimana semua elemen data telah diurutkan akan diuji satu persatu smpai ditemukan elmen data yang dibutuhkan sehingga data lebih cepat ditemukan[4][5].

A. Algoritma Binary Search

Algoritma adalah sistematika yang sifatnya berurutan secar logic (logis) untuk menyelesaikan suatu permasalahan melalui perintah-perintah yang dibuat secara jelas, Pencarian Biner (Binary search) menggunakan pencarian secara berurutan dan data yang ada sudah berurutan dan apabila belum makan pencarian tidak bisa dilakukan[6][7].

Biner merupakan struktur data dengan kata lain argument dari setiap fungsi merupakan satu kunci dan nilai dari satu nomor record yang dihubungkan dengan nuilai kunci yang diberikan dan pointer record data yang lebih sederhana[8].

\section{B. Data}

Data adalah sesuatu yang diketahui atau sudah terjadi yang merupakan fakta (bukti) dan dapat memnggambarkan suatu persoalan atau keadaan (thing Know or assumed), Data merupakan fakta atau peristiwa yang terjadi di lingkungan fisik atau suatu organisasi sebelum diolah ke dalam format yang lain sehingga mudaH dimengerti dan dipahami sehingga dapat digunakan, tsunami dta telah emrubah pemahaman tentang data dikarenakan bahan baku data begitu banyak dikarenakan perkembangan teknologi internet selama ini proses mencari, memperoleh atau memilki informasi merupakan hal yang tidak mudah[9][10]11].

C. Potensi 
Potensi dalam arti luas adalah kemampuan, daya saing, kekuatan atau kesanggupan yang dapat dikembangkan lebih luas dimasa yang akan datang [12].

D. Investasi

Investasi merupakan harapan atau penanaman modal atau dana yang dilakukan untuk memperoleh keuntungan di masa yang akan datang, Komitmen atas sejumlah uang atau sumber daya yang lain dengan harapan memperoleh keuntungan yang dilakukan saat ini dan dapat memberi manfaat di hari kemudian (Iin Futer) yang tergolong sebagai asset real (Real Aset) atau berbentuk finansial (finansial asset) berupa obligasi ataupun reksadana [13][14].

\section{E. Smartphone}

Smartphone merupakan telepon pintar yang terkoneksi dengan internet dan dapat melakukan fungsinya selayaknya komputer mini yang menyediakan fungsi personal digital assistant. Smarphone didukung oleh fasilitas-fasilitas seperti e-mail. Layar sentu, pengaturan daftar nama, layar sentuh, penghitungan cepat, pencarian lokasi, bis melihat photo dan juga memutar lagu dan penjelajahan internet[15][16].

\section{METODE PENELITIAN}

A. Metode Pengembangan Sistem

Metode Rapid Aplication Development digunakan untuk jangka waktu yang tidak lama di sesuaikan dengan pengembangan aplikasi yang, llangkah sebagai berikut:

1. Fase Perencanaan Syarat-Syarat

Pada fase ini analisis kebutuhan untuk pengidentifikasian tujuan aplikasi atau sistem serta untuk mengidetifikasi syarat-syarat informasi yang ditimbulkan dari tujuan-tujuan tersebut.

2. Fase Perancangan

Pada tahap ini perancangan proses dan perancangan antar muka dari aplikasi Perancangan proses pada aplikasi ini digambarkan oleh flowchart.

3. Fase Konstruksi

Pada tahapan ini dilakukan pengkodean terhadap rancangan-rancangan yang telah didefinisikan ke dalam suatu bahasa pemograman.

4. Fase Pelaksanaan

Pada tahapan ini diimplementasi aplikasi, pengujian aplikasi dan analisa hasil pengujian terhadap aplikasi yang juga bertujuan untuk mengetahui tingkat keberhasilan dari aplikasi dalam mencapai hasil yang diinginkan. Pengujian dan analisa hasil pengujian dilakukan berdasarkan

B. Flowchart

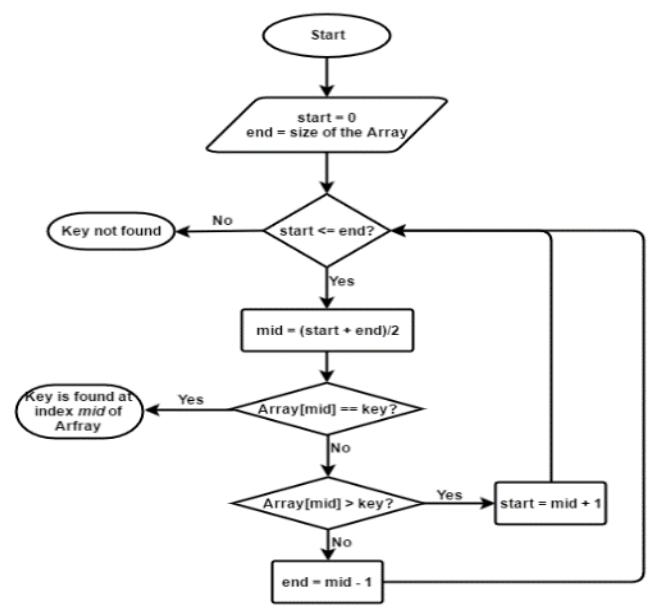

Gambar 1. Flowchar Algoritma Binary Search

C. Manual Analisis 
Salah satu syarat agar pencarian biner dapat dilakukan adalah data sudah dalam keadaan urut. Dengan kata lain, apabila data belum dalam keadaan urut, pencarian biner tidak dapat dilakukan. Dalam kehidupan sehari-hari, sebenarnya kita juga sering menggunakan pencarian biner. Misalnya saat ingin mencari suatu kata dalam kamus Prinsip dari pencarian biner dapat dijelaskan sebagai berikut :

1. Diambil posisi awal 0 dan posisi akhir $=\mathrm{N}-1$, kemudian dicari posisi data tengah dengan rumus (posisi awal + posisi akhir) / 2 .

2. Data yang dicari dibandingkan dengan data tengah. Jika lebih kecil, proses dilakukan kembali tetapi posisi akhir dianggap sama dengan posisi tengah -1 . Jika lebih besar, porses dilakukan kembali tetapi posisi awal dianggap sama dengan posisi tengah +1 .

3. Demikian seterusnya sampai data tengah sama dengan yang dicari.Untuk lebih jelasnya perhatikan contoh berikut:

Misalnya ingin mencari data 17 pada sekumpulan data berikut :

\begin{tabular}{l|l|l|l|l|l|l|l|l|l|l|}
\hline 3 & 9 & 1 & 1 & 1 & 1 & 2 & 2 & 3 & 3 \\
& & 1 & 2 & 5 & 7 & 0 & 3 & 1 & 5 \\
\hline
\end{tabular}

Mula-mula dicari data tengah, dengan rumus $(0+9) / 2=4$. Berarti data tengah adalah data ke-4, yaitu 15. Data yang dicari, yaitu 17, dibandingkan dengan data tengah ini. Karena $17>$ 15 , berarti proses dilanjutkan tetapi kali ini posisi awal dianggap sama dengan posisi tengah +1 atau 5 .

\begin{tabular}{|l|l|l|l|l|l|l|l|l|l|}
\hline 3 & 9 & 1 & 1 & 1 & 1 & 2 & 2 & 3 & 3 \\
& & 1 & 2 & 5 & 7 & 0 & 3 & 1 & 5 \\
Awal & \multicolumn{10}{c|}{ tengah }
\end{tabular}

Data tengah yang baru didapat dengan rumus $(5+9) / 2=7$. Berarti data tengah yang baru adalah data ke-7, yaitu 23. Data yang dicari yaitu 17 dibandingkan dengan data tenah ini. Karena $17<23$, berarti proses dilanjukkan tetapi kali ini posisi akhir dianggap sama dengan posisi tengah -1 atau 6.

\begin{tabular}{|c|c|c|c|c|c|c|c|c|c|}
\hline 3 & 9 & $\begin{array}{l}1 \\
1\end{array}$ & $\begin{array}{l}1 \\
2\end{array}$ & $\begin{array}{l}1 \\
5\end{array}$ & $\begin{array}{l}1 \\
7\end{array}$ & $\begin{array}{l}2 \\
0\end{array}$ & 2 & 3 & $\begin{array}{l}3 \\
5\end{array}$ \\
\hline
\end{tabular}

Data tengah yang baru didapat dengan rumus $(5+6) / 2=5$. Berarti data tengah yang baru adalah data ke-5, yaitu 17. data yang dicari dibandingkan dengan data tengah ini dan ternyata sama. Jadi data ditemukan pada indeks ke-5. Pencarian biner ini akan berakhir jika data ditemukan atau posisi awal lebih besar daripada posisi akhir. Jika posisi sudah lebih besar daripada posisi akhir berarti data tidak ditemukan.

Jumlah pembandingan minimum pada pencarian biner adalah 1 kali, yaitu apabila data yang dicari tepat berada di tengah-tengah. Jumlah pembandingan maksimum yang dilakukan dengan pencarian biner dapat dicari menggunakan rumus logaritma, yaitu : $\mathrm{C}=2 \log \mathrm{v}(\mathrm{N})$.

\section{HASIL DAN ANALISIS}

A. Hasil

1. Form Login

Form login merupakan halaman digunakan untuk membatasi hak akses hanya untuk admin yang bisa mengaksesnya, untuk melakukan proses login dibutuhkan username dan password. 
JSAI : Journal Scientific and Applied Informatics

Vol. 3, No. 3, November 2020, hal. 129-136

E-ISSN: 2614-3054; P-ISSN: 2614-3062, accredited by Kemenristekdikti, Sinta 5

DOI: 10.36085

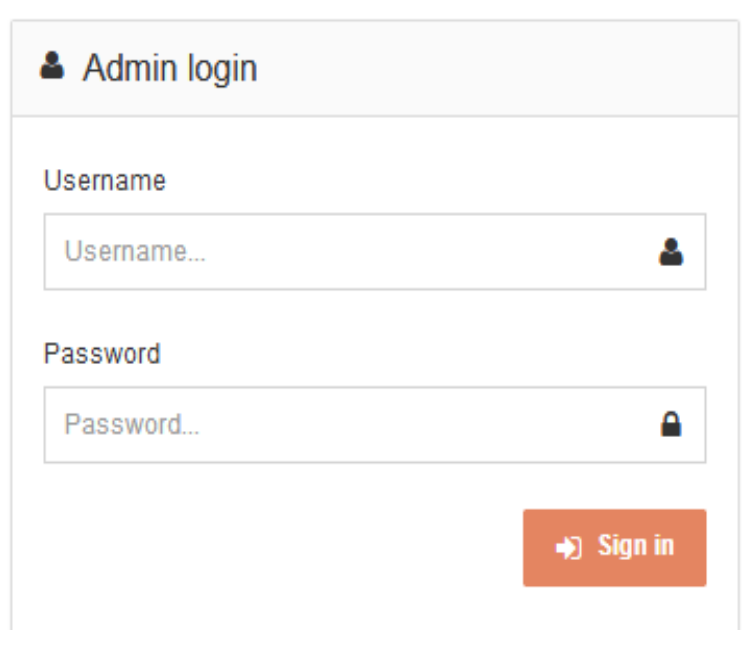

Gambar 2. Form Login

2. Form Home

Halaman home ini menampilkan artikel singkat mengenai kabupaten Seluma
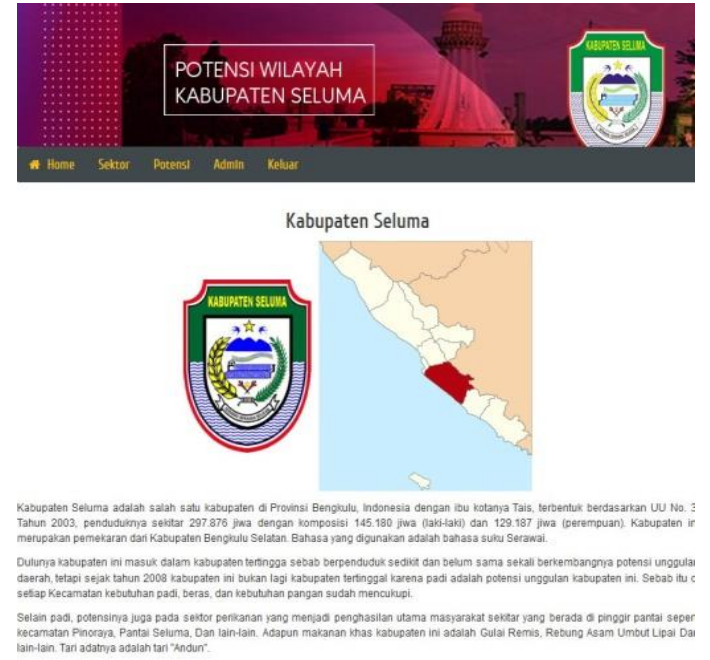

Gambar 3. Form Home

3. Form Sektor

Halaman sektor digunakan untuk menginput jenis-jenis potensi yang ada di daerah pada umumnya.
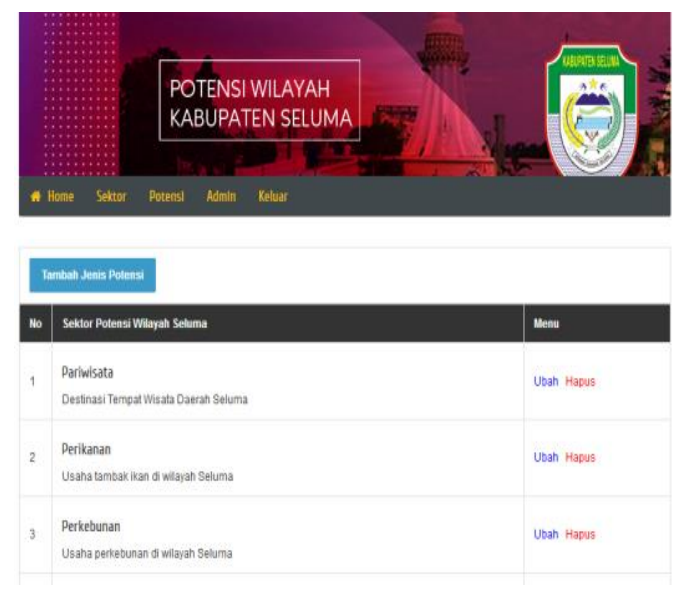

Gambar 4. Form Sektor 


\section{Form Tambah Sektor}

Untuk menambah data jenis bisa menggunakan tombol tambah sektor yang telah disediakan, aplikasi akan menampilkan halaman dengan form tambah sektor seperti berikut ini :
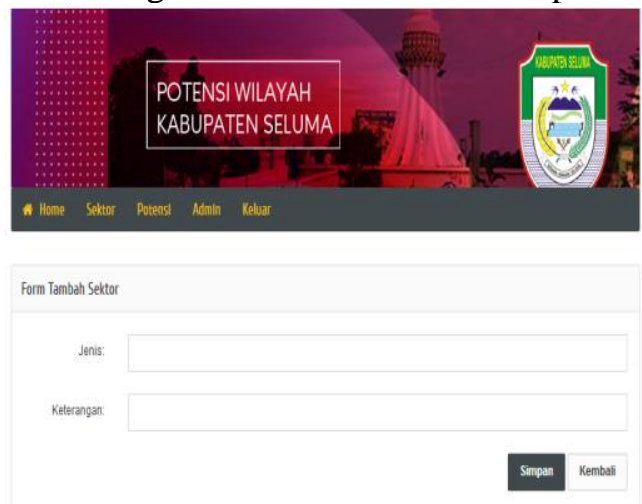

Gambar 5. Form Tambah sektor

5. Form Potensi

Form potensi adalah halaman yang digunakan untuk tambah, ubah dan hapus data komiditi. Data potensi disini adalah data komiditi wilayah seluma di bidang alam yang meliputi perkebunan, pertanian, pertambangan, perikanan dan peternakan'
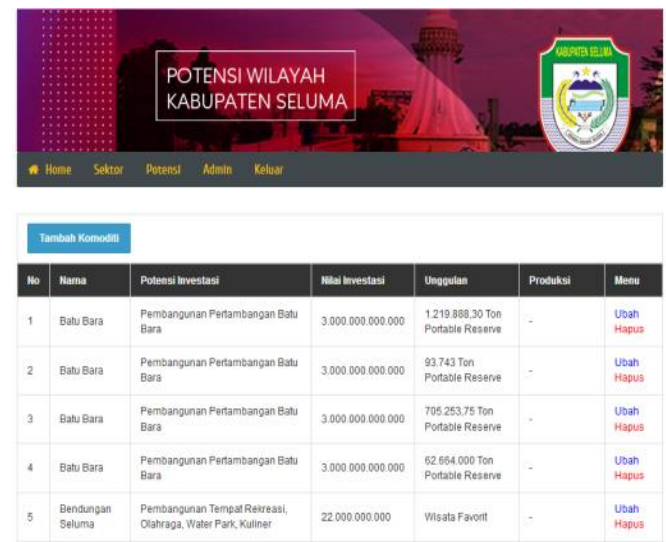

6. Form Tambah Komoditi

Gambar 6. Form Potensi

Pada Form ubah data juga terdapat form seperti tambah data tetapi setiap input teksnya telah terisi dengan data-data yang sesuai dengan data yang ingin di ubah.

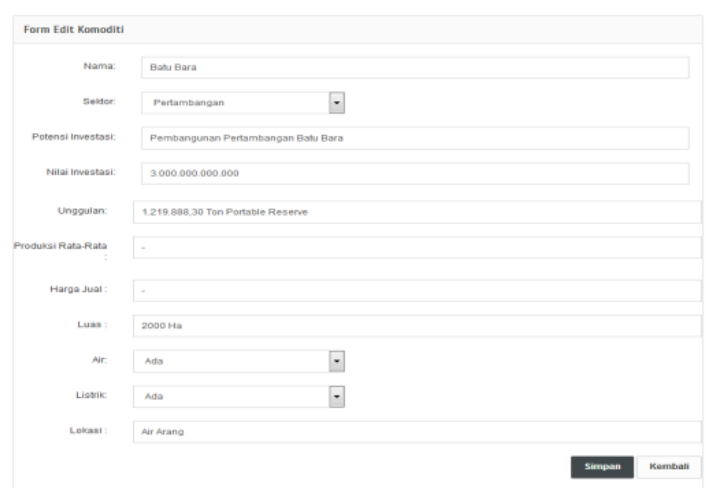

Gambar 7. Form Ubah Data Komiditi 
JSAI : Journal Scientific and Applied Informatics

Vol. 3, No. 3, November 2020, hal. 129-136

E-ISSN: 2614-3054; P-ISSN: 2614-3062, accredited by Kemenristekdikti, Sinta 5

DOI: 10.36085

7. Form Hasil Pencarian

Pada Form ini juga dilengkapi dengan kolom pencarian yang bisa digunakan untuk mencari data potensi dengan cepat dan akurat.

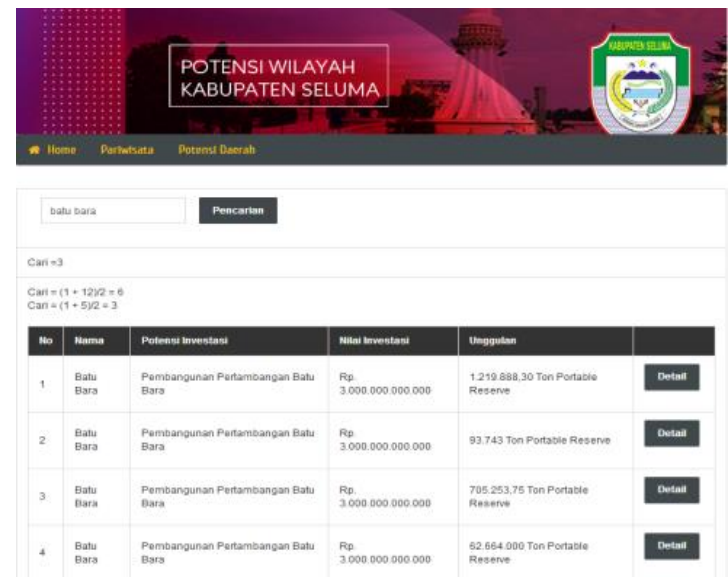

Gambar 8. Form Hasil pencarian

B. Pembahasaan

Proses pencarian dalam aplikasi menggunakan Algoritma Binary search dengan melakukan proses bagi dua, untuk melakukan pencarian dengan kata kunci Batu Bara, akan dilakukan beberapa langkah yang dibutuhkan untuk mendapatkan hasilnya, seperti berikut ini :

Diketahui, jumlah data 250 dan data batu bara ada diurutan ke 3, sehingga aplikasi akan mengitung dengan menyamakan nilai tengah terlebih dahulu.

Iterasi 1

Jumlah data $=250$ (nilai akhir)

Data Cari $=3$

Nilai tengah $=(1+250) / 2=125$

Data cari lebih kecil dari pada nilai tengah sehingga nilai akhir menjadi Nilai tengah -1

Iterasi 2

Nilai akhir $=125-1=124$

Nilai tengah $=(1+124) / 2=62$

Data cari lebih kecil dari pada nilai tengah sehingga nilai akhir menjadi Nilai tengah -1

Iterasi 3

Nilai akhir $=62-1=61$

Nilai tengah $=(1+62) / 2=31$

Data cari lebih kecil dari pada nilai tengah sehingga nilai akhir menjadi Nilai tengah -1

Iterasi 3

Nilai akhir $=31-1=30$

Nilai tengah $=(1+30) / 2=15$

Data cari lebih kecil dari pada nilai tengah sehingga nilai akhir menjadi Nilai tengah -1

Iterasi 3

Nilai akhir $=15-1=14$

Nilai tengah $=(1+14) / 2=7$

Data cari lebih kecil dari pada nilai tengah sehingga nilai akhir menjadi Nilai tengah -1

Iterasi 3

Nilai akhir $=7-1=6$

Nilai tengah $=(1+6) / 2=3$ 
Data tengah $=$ data cari yaitu 3 , maka proses pencarian selesai.

\section{KESIMPULAN}

Berdasarkan hasil pengujian : a) Potensi terbesar Kabupaten seluma adalah sektor pertanian dan peternakan (perikanan), kemudian disusul oleh pertambangan dan sektor wisata b) Kelebihan Algoritma Binary Search Efisien dan lebih cepat jika mencari suatu nilai dalam jumlah data yang besar dikarena data-data tersebut sudah diurutkan terlebih dahulu dan kompleksitas algoritmanya yang lebih kecil c) Kekurangan Binary Search yang pertama adalah data harus diurutkan terlebih dahulu agar proses pencarian bisa berjalan dengan baik dan lebih rumit

\section{UCAPAN TERIMA KASIH}

Terima kasih kepada Pemerintah Kabupaten Seluma atas kerjasama memberi data-data untuk kebutuhan pembuatan sistem ini.

\section{REFERENSI}

[1] Sugiri, Dinar, Hanny Hikmayanti, and Aries Suharso. "RANCANG BANGUN APLIKASI KAMUS SUNDA-INDONESIA DENGAN METODE BINARY SEARCH BERBASIS ANDROID." TechnoXplore: Jurnal Ilmu Komputer dan Teknologi Informasi 4, no. 1 (2019)

[2] Tandelilin, Eduardus. Portofolio dan Investasi: Teori dan aplikasi. Kanisius, 2010.

[3] Safina, Lailan, and Sri Endang Rahayu. "Analisis Pengaruh Investasi Pemerintah Dan Swasta Terhadap Penciptaan Kesempatan Kerja Di Sumatera Utara." Jurnal Manajemen \& Bisnis 11, no. 01 (2011): 111.

[4] Syahputra, Guntur. "Implementasi Teknik Binary Search Pada Kamus Indonesia-Batak Toba." Journal Of Informatic Pelita Nusantara 1, no. 1 (2016).

[5] Andri, Andri. "Penerapan Algoritma Pencarian Binary Search dan QuickSort pada Aplikasi Kamus Bahasa Palembang Berbasis Web." Jurnal Informatika: Jurnal Pengembangan IT 4, no. 1 (2019): 7074.

[6] Yusaputra, Rizky. "APLIKASI MOBILE PENCARIAN RUTE TERPENDEK LOKASI FASILITAS UMUM BERBASIS ANDROID MENGGUNAKAN ALGORITMA FLOYD-WARSHALL." PhD diss., UNIVERSITAS ISLAM NEGERI SULTAN SYARIEF KASIM RIAU, 2013.

[7] Yanto, Budi, and Erni Rouza. "PENCARIAN FILE DENGAN METODE BINARY SEARCHING DAN DENGAN PENDEKATAN WILDCARD CHARACTER." Riau Journal Of Computer Science 3, no. 1 (2017): 1-8.

[8] Ridwan, Ridwan. "IMPLEMENTASI TYPING GAME MENGGUNAKAN ALGORITMA BINARY SEARCH." PhD diss., Universitas Teknologi Yogyakarta, 2018.

[9] Situmorang, Syafrizal Helmi, Iskandar Muda, M. Doli, and Fanzie Syarief Fadli. Analisis data untuk riset manajemen dan bisnis. USUpress, 2014.

[10] Kuliah, Materi. "Sistem informasi manajemen." Bina Nusantara. Jakarta (2005).

[11] Susanto, Sani, and Dedy Suryadi. "Pengantar data mining: mengagali pengetahuan dari bongkahan data." (2010).

[12] Soleh, Ahmad. "Strategi Pengembangan Potensi Desa." Jurnal Sungkai 5, no. 1 (2017): 32-52.

[13] Andina, Nadia Putri. "Pengaruh Keputusan Investasi, Keputusan Pendanaan, dan Kebijakan Dividen Terhadap Nilai Perusahaan." PhD diss., Universitas Widyatama, 2015.

[14] Tandelilin, Eduardus. "Dasar-dasar Manajemen Investasi." (2010).(Investasi)

[15] Mokalu, Juniver V., Norma N. Mewengkang, and Joane PM Tangkudung. "Dampak Teknologi Smartphone Terhadap Perilaku Orang Tua di Desa Touure Kecamatan Tompaso." ACTA DIURNA KOMUNIKASI 5, no. 1 (2016).

[16] Budiono, Fahrizal Lukman. "Persepsi dan Harapan Pengguna terhadap Kualitas Layanan Data pada Smartphone di Jakarta." Buletin Pos Dan Telekomunikasi 11, no. 2 (2013): 93-108. 